\title{
Nurturing Problem Posing in Young Children: Using Multiple Representation within Students' Real-World Interest
}

\author{
Hyunkyung Kwon $^{1 \star}$ (D), Mary Margaret Capraro ${ }^{1}$ (D)
}

\author{
${ }^{1}$ Texas A\&M University, USA \\ *Corresponding Author: kwonx133@tamu.edu
}

Citation: Kwon, H., \& Capraro, M. M. (2021). Nurturing Problem Posing in Young Children: Using Multiple Representation within Students' RealWorld Interest. International Electronic Journal of Mathematics Education, 16(3), em0648. https://doi.org/10.29333/iejme/11066

\begin{tabular}{|c|c|}
\hline ARTICLE INFO & ABSTRACT \\
\hline Received: 31 Jan. 2021 & Problem-posing activities have been shown to motivate students' learning while promoting a multifaceted and \\
\hline Accepted: 8 May 2021 & $\begin{array}{l}\text { interesting educational environment. Moreover, these activities enable students to be engaged in personal } \\
\text { interpretations of their own mathematical thinking. The purpose of this study was to determine if using a hands- } \\
\text { on learning intervention with multiple representations could improve students' problem-posing skills. The } \\
\text { researchers examined the answers of the participants }(n=14) \text { with the greatest increase in scores from pre to } \\
\text { posttest after participating in } 20 \text { problem-posing intervention activities to determine how the intervention } \\
\text { allowed students to pose valid, real-world semi-structured problems. The researchers qualitatively analyzed the } \\
\text { posed problems for logical real-world contexts and the alignment of the setup of each problem to determine if the } \\
\text { students' posed problems were logical and solvable. Results from this study confirm that students were able to } \\
\text { build stronger understanding of mathematical content when they were engaged in authentic problem-posing } \\
\text { activities that were meaningful to them. Thus, teachers need to include purposeful and focused problem-posing } \\
\text { activities into their classroom lessons. }\end{array}$ \\
\hline
\end{tabular}

Keywords: problem posing, multiple representation, real-world application

\section{INTRODUCTION}

Previous researchers have focused on various aspects of mathematical problem posing within elementary school environments. Kafai et al. (1998), and Lowrie (2005) both examined elementary students as they posed problems in a game-based environment. Similarly, Yamamoto et al. (2012) studied an interactive learning environment populated with first graders, who demonstrated their ability to pose problems within a virtual environment. Research has also suggested that young children in Grades 1 and 3 can create increasingly sophisticated one- and two-step problems reflecting their interests in a multifaceted and exciting learning environment when encouraged by their teachers (Lowrie, 2002a, 2005). Studies have also been conducted on older students; for example, one researcher found that Singaporean upper elementary students were able to pose more complex problems as they advanced from fourth to sixth grade (Cai, 2003). Thus, the current consensus among researchers is that, when properly motivated through the use of effective pedagogical strategies, students at the elementary level are capable of posing solvable real-world problems.

The traditional approach to mathematics instruction is to ask students to solve preselected problems. Mathematics teachers generally either write their own problems or use problems from textbooks or other sources. As a result, students in most classrooms currently do not take responsibility for creating their own mathematics problems. This is unfortunate, because enabling students to take an active role in creating their own problems allows them to enjoy mathematics learning and promotes a multifaceted and interesting learning atmosphere as they engage in personal interpretations of their own mathematical thinking (Cai, 2003; Kilpatrick, 1987; Lowrie, 2002b, 2005; Singer, Ellerton, \& Cai, 2013; Stoyanova \& Ellerton, 1996). Another benefit of problem-posing instruction is that the 21st century skills of communication, critical thinking, and creativity are also employed by students as they pose problems about the world around them (Alismail \& McGuire, 2015; Partnership for 21st Century Learning, 2019). A recent document titled Catalyzing Change in Early Childhood and Elementary Mathematics: Initiating Critical Conversations (National Council of Teachers of Mathematics [NCTM], 2020) supports "Broadening the purpose of school mathematics to prioritize development of deep conceptual understanding so that children experience joy and confidence in themselves as emerging mathematicians" (p. xiii). We see posing problems as a strategy that allows students to be engaged in activities that require them to develop deep understanding as opposed to problem solving, which in many classrooms only requires a surface understanding and the application of rote formulas of mathematical concepts. These many benefits of problem posing have not gone unnoticed by policy makers. In fact, the Principles and Standards for School Mathematics (NCTM, 2000) stated that teachers should provide 


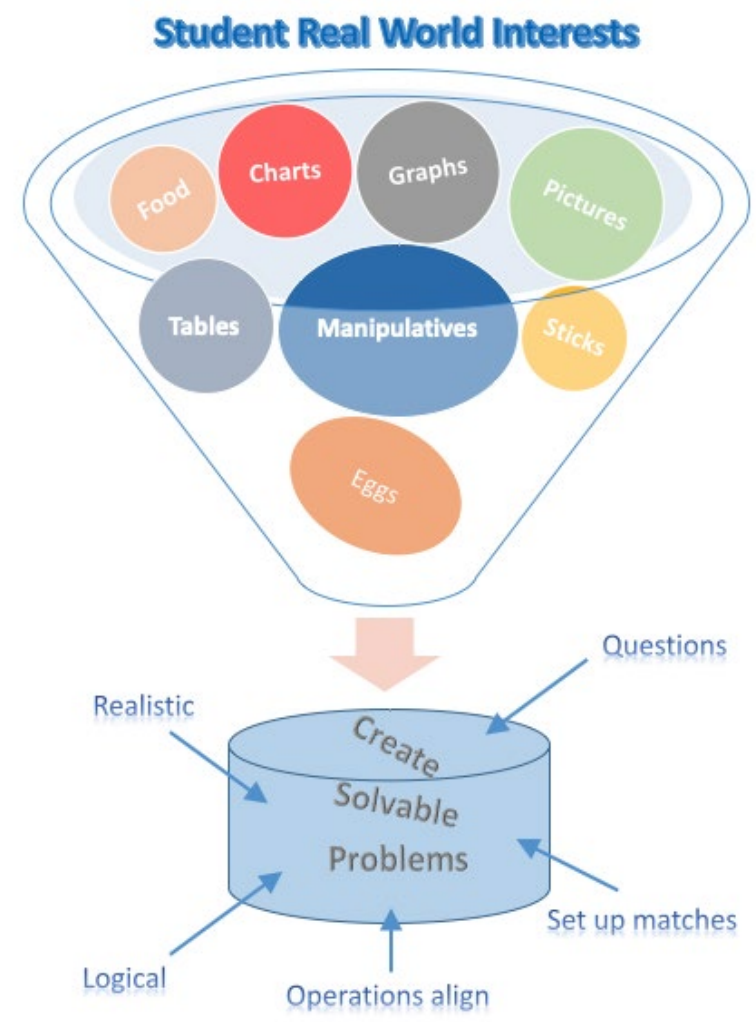

Figure 1. Theoretical Framework Model

students with opportunities to "formulate interesting problems based on a wide variety of situations, both within and outside mathematics" (p. 258). Interestingly, NCTM's book, Taking Action: Implementing Effective Mathematics Teaching Practices in Kgrade 5 (Huinker \& Bill 2017), stated that most teachers believe their students need to justify their mathematical ideas by sharing their reasoning and should "do mathematics" connected to their daily lives. These findings suggest that many educators now support problem-posing activities in which students must justify their posed problems, share their solution strategies with their peers and teachers, and use multiple representations when posing mathematical problems but do not necessarily implement them in their classrooms perhaps due to a lack of knowledge or training.

The benefits of including problem-posing activities in classroom instruction are clear and widely agreed upon (Cai \& Hwang, 2020; Xu et al., 2019). Our study will examine fourth graders during a year-long, semi-structured problem-posing intervention (Stoyanova \& Ellerton, 1996). Figure 1 pictorially outlines the theoretical framework for our study. The bowl of the funnel contains examples of some of the prompts used in our semi-structured problems employed during the intervention to motivate and engage students in posing solvable problems. We used the criteria under the funnel to evaluate the solvability of the students' problems. This figure supports the theoretical importance of our study, which focuses on engaging students in hands-on learning using multiple representations within a real-world context as a way to nurture young children's thinking to encourage posing valid solvable problems.

\section{LITERATURE REVIEW}

\section{Hands-on Learning}

Hands-on learning is an instructional approach where students manipulate concrete objects to understand and learn (Haury \& Rillero, 1994). Hands-on activities can involve using simple objects or everyday gadgets. Unlike traditional teaching methods where students just listen to the teacher, students are engaged in the learning process while using objects during hands-on learning (Clark \& Clark, 2020; Holstermann, Grube, \& Bogeholz, 2010; Lebuffe, 1994), which enables them to be active learners rather than passive learners. There are many benefits of using hands-on learning in mathematics classrooms. One is increased learning opportunities for diverse learners because students are able to touch, see, and feel the concrete object they are learning with. In one study, hands-on activities were more effective for visual and kinesthetic learners, slow readers, and English-language learners (Carbonneau, Marley, \& Selig, 2013). Additionally, students are more stimulated and motivated to learn during hands-on activities because they find learning to be more exciting and more realistic and thus become more engaged in the lesson (Franklin \& Peat, 2005; Krapp, 2005; Nott \& Wellington, 1996; Thorsteinsson \& Page, 2018). When used as a supplement to a traditional teaching approach, hands-on learning has the potential to improve learning for many students who struggle with learning from lectures as well as increase engagement for all. 
Hands-on learning techniques, such as using manipulatives, have been widely used to introduce concepts in elementary mathematics classrooms. Research findings support doing so. In some studies, Cuisenaire rods, dice, tiles, geometric shapes, fraction tiles, and other manipulative materials helped students visualize mathematical concepts, construct meaning, and possess a better conceptual understanding of abstract facts (Bruner, 1964; Carbonneau et al., 2013). Other studies concluded that a handson learning approach not only increases a student's ability to think critically but to also have a more concrete and clear understanding of abstract knowledge (Chowrira et al., 2019; Haury \& Rillero, 1994). These findings are significant because elementary school students generally have a difficult time understanding abstract concepts. In addition, hands-on learning assists students in building connections between the object they are interacting with, symbols, and mathematical ideas (National Research Council, 2001). Therefore, when teachers use hands-on learning activities in their mathematics classrooms, students can have a better conceptual understanding of mathematical concepts. In our study, during each of the intervention activities, students used hands-on materials with which they could visualize the mathematical concepts being studied before posing a problem.

\section{Using Multiple Representations}

Prior researchers (e.g., Hoffler \& Leutner, 2007; Malone et al., 2020; Otten et al., 2019) have found that students learn more conceptually from words reinforced by objects and pictures than from words alone. Employing multiple representations to make connections between pictures, tables, graphs, symbols, and verbal explanations of mathematical relationships will enable and at the same time assist students in developing a greater understanding of mathematical concepts and connections (Van Meter et al., 2020; NCTM, 2000; Porzio, 1999). There is a common understanding that employing various mathematical manipulatives and visuals and converting between them is necessary for students to develop conceptual understandings in mathematics (Ainsworth, Bibby, \& Wood, 2002; Van Meter et al., 2020). Furthermore, using mathematical representations allows learners to "acquire a set of tools that significantly expand their capacity to model and interpret physical, social, and mathematical phenomena" (NCTM, 2000 , p. 4). Early exposure to multiple representations of mathematical concepts is thus beneficial to long-term mathematical learning.

Even at their stage of learning, elementary students should be developing and connecting multiple representations to generalize mathematical problems (Swafford \& Langrall, 2000). However, most first graders in one study were only able to find single solutions to mathematical problems even though the questions posed required a general pattern formulation (Deliyianni et al., 2009). In general, although primary school children possess strong insights and sense-making tools, mathematics teachers struggle to help these students concretely represent and display abstract mathematics topics (Lesh \& Harel, 2003). Through our study, we attempted to familiarize students with the act of switching between multiple representations of a mathematics concept to enable them to make sense of their insights when posing problems.

\section{Real-World Applications}

Real-world application is a teaching practice that seeks to increase students' mathematical skills. Real-world application problems allow students to understand the practical uses and concrete purposes for the knowledge and skills learned in their classes by allowing them to relate what they are learning to their own lives and the larger societal context (Bardini, Pierce, \& Stacey, 2004; Lee, 2012). Because students are able to put themselves in the context of the problem, they are able to make stronger connections to real-world situations compared to students who only engage with traditional teaching methods (Hidi, 1990). Furthermore, real-world scenarios can be fun to students, which allows them to be motivated to learn (NCTM, 2007; Premadasa \& Bhatia, 2013; Zbiek \& Connor, 2006), and this method of instruction encourages more engaged learning by connecting to student interests directly (Stillman, Brown, \& Galbraith, 2008). This, in turn, helps students be able to more effectively remember what they learn (Lee, 2012). Finally, real-world applications of learned knowledge help students be more prepared for solving problems that they will encounter in the real-world, which broadens their learning capabilities (Pedley, 2005). The intervention activities used in our study utilized real-world application to promote the connection of mathematical skills and concepts in students while posing their problems.

\section{Problem Posing}

There are many benefits to problem posing connected to students' mathematical learning. Problem posing can increase students' problem-solving skills, attitudes, and confidence in mathematics (Cai, 2005; Cifarelli \& Sevim, 2015; English, 2020; Silver \& Cai, 1996). Additionally, posing mathematical problems can promote the development of mathematical aptitude and learning autonomy (Kilpatrick, 1987; Mamona-Downs \& Downs, 2005). Students can also collaborate with their peers when posing problems, and this is where the social component emerges in learning (English, 2003). Specifically, students can discuss and evaluate the different approaches that have been presented by other classmates. Therefore, problem-posing activities should be used as an essential part of classroom mathematics instruction.

Problem posing can be especially beneficial for younger students. This is because young students are sensitive to the context in which mathematical notions are presented to them compared to those in the later stages in their learning (Chapman, 2006). Promoting problem posing in younger students' mathematics classrooms may encourage them to develop metaphors to link mathematics with their out-of-school experiences (Quintero, 2004). This is important because previous research found that when some students were not able to solve simple addition and subtraction problems when they were presented in decontextualized problems, they were able to provide correct answers when the problems were connected to real-life situations.

A teacher's role is important in problem-posing activities. There are three criteria that teachers should consider when they implement problem-posing activities in their mathematics classrooms: fluency, originality, and complexity (Silver \& Cai, 2005). Fluency refers to the solvable problems posed that meet the parameters of the assignment. Originality relates to the mathematical 
creativity that is demonstrated in the posed problem. Lastly, complexity considers the sophistication of the mathematical relationships established by the problem poser. Teachers should keep these three important criteria in mind when guiding students to produce sophisticated problems. In our study, we used the classification of semi-structured problem posing by Stoyanova and Ellerton (1996), which is "the process by which, on the basis of mathematical experience, students construct personal interpretations of concrete situations and formulate them as meaningful mathematical problems" (p. 519).

\section{Valid Semi-Structured Problem Posing}

Posed problems have been defined and categorized differently by various researchers. Stoyanova and Ellerton (1996) defined three categories of problem-posing experiences: (a) free situations, (b) semi-structured situations, and (c) structured problemposing situations. Silver (1994) based his classifications within a problem-solving context, classifying problem posing by whether it happened before (pre-solution), during (within-solution), or after problem solving (post-solution). He maintained that problem posing occurred (a) prior to problem solving when students create problems from a certain object (i.e., story, picture, table, graph, or another representation); (b) during problem solving when students are required to purposefully change the focus of the problem, such as when "finding a pattern"; and (c) after problem solving when understandings gained are used in new settings. Christou, Mousoulides, Pittalis, Pitta-Pantazi, and Sriraman (2005) combined the work of these former researchers and discussed five possible categories for problem posing: (a) general problems (free), (b) problems with specific answers, (c) problems with definite information, (d) questions for problem situations, and (e) problems aligned to specific calculations. Cristou et al. (2005) also defined four processes of problem posing: (a) editing quantitative information, (b) selecting quantitative information, (c) comprehending and organizing quantitative information, and (d) translating quantitative information.

Some researchers have sought to simplify or redefine the categories put forth by these early researchers. Kuzle, Gebel, and Rott (2018) suggested combining free and semi-structured problem posing because they found it difficult to distinguish between the two. Similarly, Kilic (2013) recommended a problem-posing model that was a mixture of the classifications of Stoyanova and Ellerton (1996) and Christou et al. (2005). Specifically, Kilic (2013) defined problem-posing categories as such: free problem posing (where students pose challenging problems based on specific numbers or operations), semi-structured problem posing (based on stories or graphs with no restrictions), and structured problem posing (based on predetermined answers or given equations). As can be seen, various researchers have defined and categorized problem posing activities differently; thus, it is important for future researchers to specifically define their problem posing studies clearly.

The focus of our study is on semi-structured problem-posing activities in which students are provided specific open-ended situations (i.e., "pose a problem") and are required to create problems based on specific items (e.g., a menu, a picture, a graph, etc.) and particular guidelines (e.g., one- or two-step problem). Semi-structured problem-posing situations "refer to the ones in which students are provided with an open situation and are invited to explore the structure of that situation, and to complete it by using knowledge, skills, concepts, and relationships from their previous mathematical experiences" (Ulusoy \& Kepceoğlu, 2018, p. 1940). Within our problem-posing activities, elementary students were given types of mathematical and/or non-mathematical representations, such as pictures, tables, graphs, equations, menus, food items, or stories associated with everyday life. Given the various categories and processes for analyzing problems posed, it is necessary to specifically define our framework for assessing posed problems as valid. We used a definition provided by Cai et al. (2013): a valid problem is a posed problem that aligns the conditions in the task and can be solved using the information provided in the problem-posing situation. In our study, elementary students were asked to pose problems using real-world information we provided (picture/menu) and supply a setup (an equation that matches the posed problem leading to a correct solution) that matched their problem posed. If these two conditions were met, we considered the problem as valid. Therefore, the research question focusing this study is the following: How did engaging fourth-grade students in multiple representations and hands-on activities enable them to pose valid, real-world semi-structured problems?

\section{METHODOLOGY}

\section{Intervention}

The intervention consisted of 20 unique problem-posing lessons connected to specific mathematics content. The problemposing sessions provided opportunities for the researchers to develop students' awareness of how problems are structured. Students received weekly lessons for an entire school year, with 10 lessons occurring during the spring semester and 10 lessons taking place during the fall semester, for a total of 20 intervention activities. Each lesson duration was approximately 15-20 minutes. The lessons used multiple representations, and all activities involved hands-on manipulatives that engaged students kinesthetically in the mathematics topics. Examples of some lessons are included in the Appendix along with the representations and hands-on activities employed. One full lesson based on Halloween activities is also included in the Appendix. Each activity used in the intervention was connected to students' real-world interests (e.g., holidays, toys, pictures, menus, newspaper ads, etc.). All lessons were based on the fourth-grade scope and sequence, and the researchers designed activities that were aligned with the scope and sequence of the grade level as well as state standards.

\section{Participants}

Convenience sampling was used in this study. Participants in this study were the fourth-grade students from a small school district in central Texas. Demographics for the school district were as follows: 19\% African American, 58\% Hispanic, 20\% White, and $2 \%$ Other, with $70 \%$ classified as "at risk." These demographics were reflective of our participant population. Students in the fourth grade were randomly assigned to a problem-posing intervention to determine the effectiveness of engaging fourth-grade 
Table 1. Problem Posing Rubric

\begin{tabular}{|c|c|c|c|c|}
\hline & Unsatisfactory (0) & Minimal (1) & Moderate (2) & Satisfactory (3) \\
\hline $\begin{array}{l}\text { Logical real- } \\
\text { world context }\end{array}$ & $\begin{array}{l}\text { No response or } \\
\text { nonsense. }\end{array}$ & $\begin{array}{l}\text { No questions implied or non- } \\
\text { solvable problem but appears to } \\
\text { use given information. } \\
\text { Ex. There are seven cows. }\end{array}$ & $\begin{array}{l}\text { Logical/realistic problem posed but } \\
\text { did not follow instructions or did } \\
\text { not finish question. } \\
\text { Ex. There are seven cows and two } \\
\text { horses. }\end{array}$ & $\begin{array}{l}\text { Logical/realistic solvable } \\
\text { problem posed that followed } \\
\text { the instructions. } \\
\text { Ex. There are seven cows and } \\
\text { two horses. How many animals } \\
\text { are there together? }\end{array}$ \\
\hline $\begin{array}{l}\text { Setup aligned } \\
\text { with correct } \\
\text { operation }\end{array}$ & $\begin{array}{l}\text { No setup to solve } \\
\text { the problem. }\end{array}$ & $\begin{array}{l}\text { Setup does not align to the } \\
\text { problem posed (completely wrong } \\
\text { operation but numbers aligned). }\end{array}$ & $\begin{array}{l}\text { Setup matches the problem posed } \\
\text { with minor errors (either wrong } \\
\text { operation or switched order). }\end{array}$ & $\begin{array}{l}\text { Setup matches the problem } \\
\text { posed and is correct. }\end{array}$ \\
\hline
\end{tabular}

students in interventions based on real-world multiple representations and manipulatives for the purpose of improving their problem-posing skills. Only students who participated in the problem-posing intervention and completed both the pre and posttest administered during the study $(n=80)$ were considered for inclusion in the current study. Student data were collected only from participants with IRB parental consent. Ultimately, the participants selected for analysis in the current study $(n=14)$ were those who had the greatest gains from pretest to posttest to determine what particular strategies helped the students effectively pose logical and solvable problems.

\section{Instrument}

The researchers administered a pretest at the beginning of the intervention (September, 2018) and a posttest at the end of the intervention (May, 2019). The tests consisted of four identical problem-solving and two identical problem-posing tasks. The level of the tasks was adapted for fourth-grade students based on their expected mathematical abilities. The Cronbach alpha reliability of the instrument was .77, which shows that it is statistically reliable and valid (Cronbach \& Shavelson, 2004). The construct validity of the tasks was vetted by two mathematics education professors from another university.

For the purposes of this study, we only focus on the results from the problem-posing tasks. Two researchers assessed the problem-posing tasks from both the pretest and posttest using a rubric to ascertain inter-rater reliability (see Table 1). The rubric focused on determining if students posed semi-structured problems within a logical real-world context ( 3 points) and if their problem setup (i.e., equation) was aligned with the correct operations (3 points). Each problem-posing task was worth a total of 6 points. If these criteria were met, their posed problems were considered logical and solvable.

On the pre and posttests, participants were required to complete two problem-posing tasks. The first one (Task A) provided students with a picture of a cake with $1 / 4$ of the cake missing. Students were asked to write a one-step problem using the picture and then write their setup of the problem. The second, Task B, presented students with a menu from a restaurant with four types of sandwiches and prices of each sandwich. Students are allotted $\$ 20$ and were asked to write a two-step problem and a setup for their posed problem. Students were not required to solve either of their posed problems.

\section{Analysis}

A total of 80 students completed both the pre and posttests. Among those students, we examined the answers of the participants with the greatest increase in scores from pre to posttest after participating in 20 problem-posing intervention activities $(n=14)$. The researchers qualitatively analyzed (Holsti, 1968) the 28 posed problems-two from each of the students. This analysis involved examining the posed problems and setup for the presence of a logical real-world context and the alignment of the setup to the problem to determine if the students' posed problems were logical and solvable. Researchers first scored on their own and obtained an inter-rater reliability of .99, which suggests that the level of agreement was almost perfect (McHugh, 2012). They then discussed the posed problems on which they disagreed during the first round of analyzing the data until they agreed $100 \%$.

\section{RESULTS}

The participants selected for analysis in the current study $(n=14)$ had score differences that ranged from 8 to 11 , which was determined after examining their posed problems using rubric components (see Table 2). All of these 14 students were able to increase their scores in the realistic- and operations-aligned factors from pre to posttest. Four students had an eight-point gain, two students a nine-point gain, five students a 10-point gain, and three students an 11-point gain. There were only three students who were able to pose logical and solvable problems (the grey column) with perfect scores for both Task A and Task B during the posttest. On the pretest, no students were able to pose logical and solvable problems. However, on the posttest, there were eight students who were able to pose a valid semi-structured problem when presented with a picture (Task A) and six students who were able to pose a valid semi-structured problem when presented with a table/menu (Task B). 
Table 2. Students' pre and posttest score difference

\begin{tabular}{|c|c|c|c|c|c|c|c|c|c|c|}
\hline \multirow{3}{*}{$\begin{array}{l}\text { Students } \\
\text { (Score } \\
\text { difference) }\end{array}$} & \multicolumn{4}{|c|}{$\begin{array}{l}\text { Logical/Situated in a real-world context } \\
\text { (Realistic) }\end{array}$} & \multicolumn{4}{|c|}{$\begin{array}{c}\text { Setup matches } \\
\text { (Operations aligned) }\end{array}$} & \multirow{2}{*}{\multicolumn{2}{|c|}{$\begin{array}{c}\begin{array}{c}\text { Logical/Solvable problem } \\
\text { (Valid problem) }\end{array} \\
\text { Post } \\
\end{array}$}} \\
\hline & \multicolumn{2}{|c|}{ Pre } & \multicolumn{2}{|c|}{ Post } & \multicolumn{2}{|c|}{ Pre } & \multicolumn{2}{|c|}{ Post } & & \\
\hline & $\mathrm{A}$ & $\mathrm{B}$ & $\mathrm{A}$ & $B$ & $A$ & $\mathrm{~B}$ & $A$ & $B$ & $\mathrm{~A}$ & B \\
\hline $1(11)$ & 0 & 0 & 3 & 3 & 0 & 0 & 3 & 2 & + & - \\
\hline $2(11)$ & 0 & 0 & 3 & 3 & 0 & 0 & 3 & 2 & + & - \\
\hline $3(11)$ & 0 & 0 & 3 & 2 & 0 & 0 & 3 & 3 & + & + \\
\hline $4(10)$ & 0 & 0 & 2 & 3 & 0 & 0 & 2 & 3 & - & + \\
\hline $5(10)$ & 0 & 0 & 3 & 3 & 0 & 0 & 2 & 2 & - & + \\
\hline $6(10)$ & 0 & 0 & 2 & 3 & 0 & 0 & 2 & 3 & - & + \\
\hline $7(10)$ & 1 & 1 & 3 & 3 & 0 & 0 & 3 & 3 & + & + \\
\hline $8(10)$ & 1 & 0 & 3 & 3 & 0 & 0 & 3 & 2 & + & - \\
\hline $9(9)$ & 0 & 0 & 3 & 3 & 0 & 0 & 1 & 2 & - & - \\
\hline $10(9)$ & 1 & 0 & 3 & 3 & 0 & 0 & 2 & 2 & _ & - \\
\hline $11(8)$ & 1 & 1 & 3 & 3 & 1 & 1 & 3 & 3 & + & + \\
\hline $12(8)$ & 0 & 0 & 3 & 0 & 0 & 0 & 3 & 2 & + & - \\
\hline $13(8)$ & 0 & 0 & 3 & 1 & 0 & 0 & 3 & 1 & + & - \\
\hline $14(8)$ & 2 & 0 & 2 & 3 & 0 & 0 & 3 & 2 & - & - \\
\hline
\end{tabular}

5. Create a one-step word problem (tell a story) using the cake picture given. Set up your problem, but do NOT solve it.

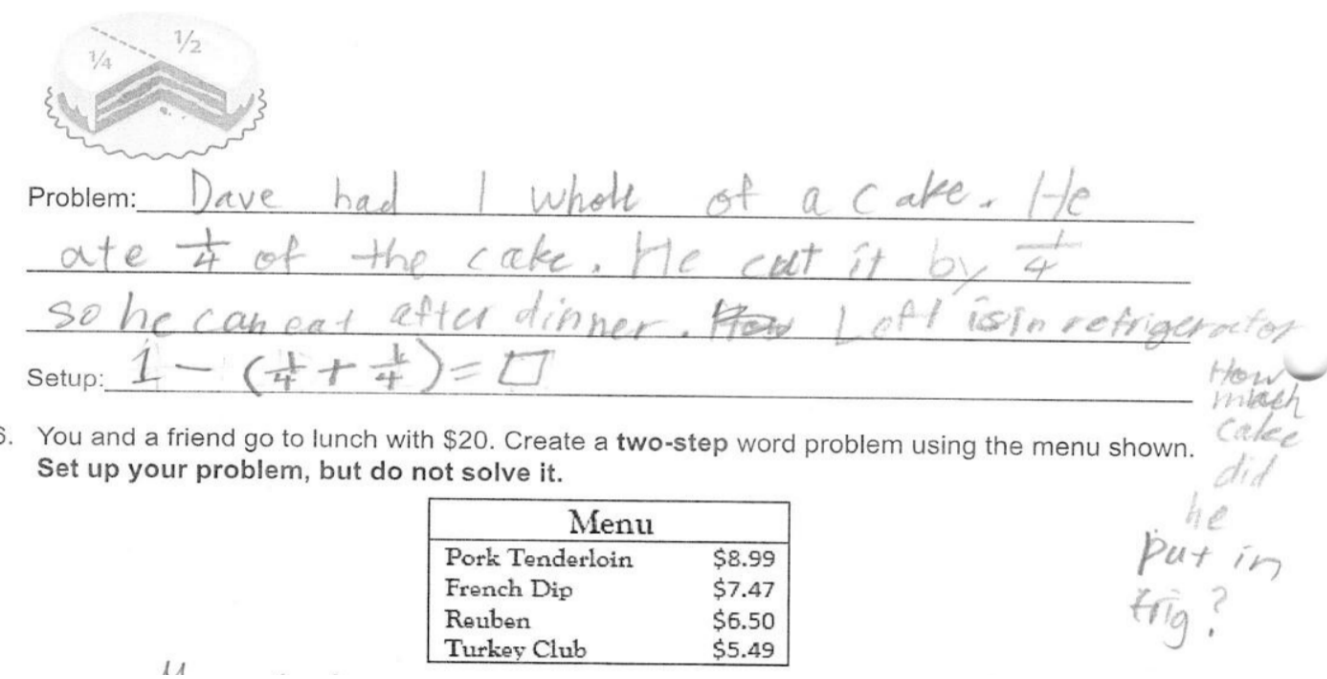

Figure 2. A student's posed problem for Task A

In order to pose a problem for Task A, students needed to possess an understanding of fractions, which is generally a difficult concept for elementary school students. In Figure 2, the student is able tell his story and solve and set up the problem correctly. He technically is posing and setting up a two-step problem, but with his sophisticated use of parentheses, he sees it as a one-step problem. He represents the whole cake as " 1 " and then puts $(1 / 4+1 / 4)$ to represent the $1 / 4$ that was missing in the original problem picture prompt and the $1 / 4$ that he ate after dinner and asks others to tell how much cake is left in the refrigerator. This sophistication of solving and setting up was practiced during the 20 intervention activities when students were asked to pose a problem in both an oral and written format when provided with pictures to base their posed problems on. They also matched setups to problems, which provided them with multiple representations to choose from. At first, many students did not connect a question to their problem, and their classmates needed to remind them that they had nothing to solve when they exchanged problems with their peers. Activities requiring students to match written problems with setups provided extra practice, which seemed to pay off.

Although students posed problems within a real-world, semi-structured logical context for Task B, a majority of the students $(n=7)$ had difficulty writing the correct setup for the equation that matched their posed problem. Many of these students $(n=5)$ wrote "b - \$20" instead of “\$20 - b" (see Figure 3). Even though these students showed sophistication in writing their posed problem and the use of variables in the first half of the setup, they were unable to correctly write a second half of the setup that would result in a correct answer.

By engaging with real-world objects and using hands-on learning experiences along with multiple representations during the intervention activities, students demonstrated confidence in their learning, which enabled them to write valid semi-structured problems at the end of the intervention. The hands-on learning experiences with concrete objects during the intervention allowed students opportunities to pose problems with various multiple representations (pictures, charts, graphs, objects, tables, etc.). For example, students were given concrete manipulatives, such as color chips and cubes, and were asked to pose a mathematical problem. Students were able to visualize the mathematical concepts through those concrete manipulatives, which allowed them 
6. You and a friend go to lunch with $\$ 20$. Create a two-step problem using the menu shown. Set up your problem, but do not solve it.

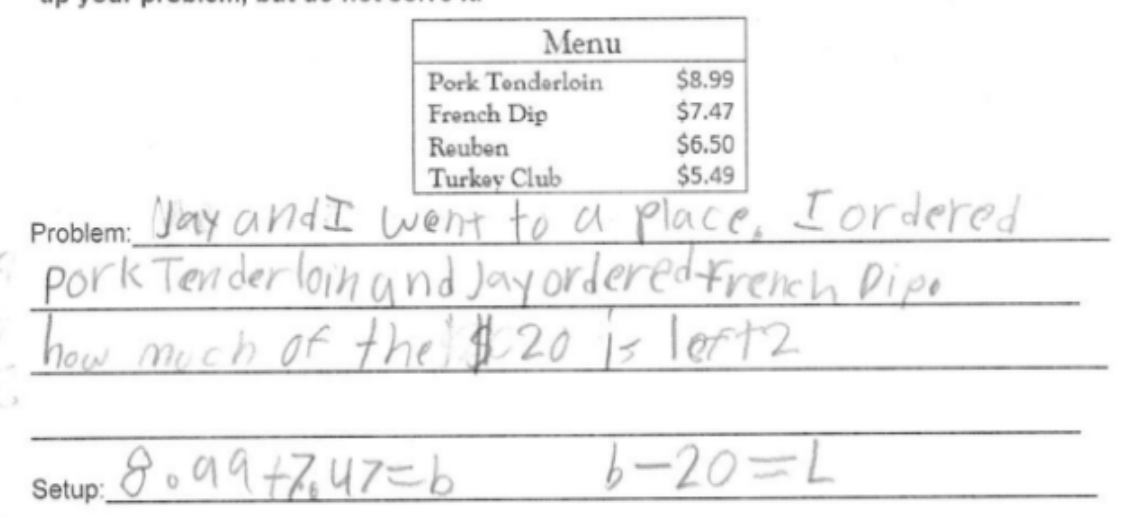

Figure 3. A student's posed problem for Task B

5. Create a one-step word problem (tell a story) using the cake picture given. Set up your problem, but do NOT solve it.

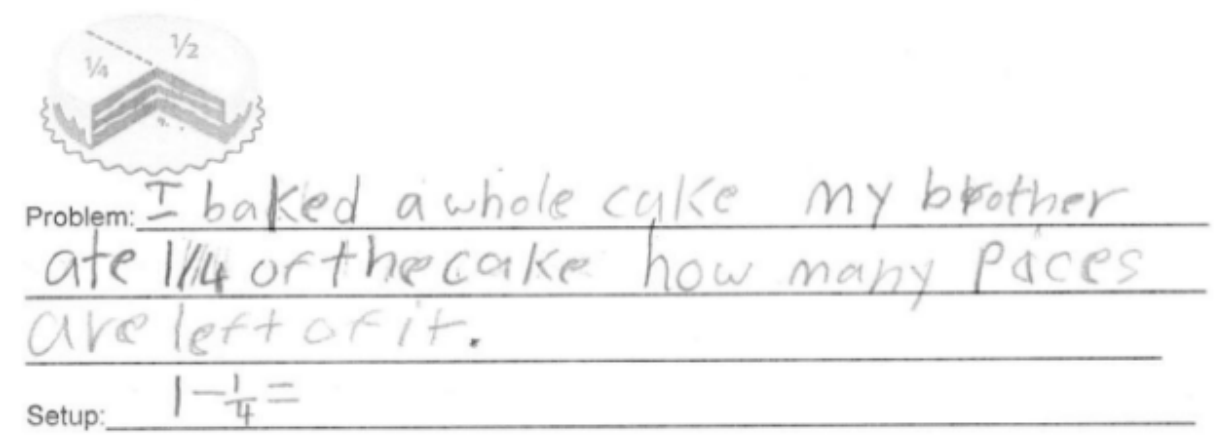

Figure 4. Another student's posed problem for Task A

to bridge the gap between concrete and abstract mathematics. To demonstrate this, students had to move from the concrete to the pictorial during the intervention activities. We also required students to write a matching setup during the intervention, which encouraged them to think at the abstract level of mathematics. These two conditions (the real-world situations and correctly matching setup) were used to assess whether their semi-structured problems were considered valid. This may have helped students to pose valid/solvable problems on the posttest.

Numerous students on the pretest were not able to pose a mathematical problem using multiple representations or only described part of the context and failed to entirely situate the context within a logical problem. For example, one student wrote, "I ate $1 / 4$ of the cake at the party," but failed to either describe the amount of the cake that they started with or ask a question to solve; thus, their written statement was not a logical posed problem centered in a real-world situation. Another student (see Figure 4) used different units for describing the cake context of the problem (fractions) and then asked how many pieces were left in the setup, resulting in a fractional answer, not a number of pieces. This made the posed problem neither logical nor valid.

In general, students on the pretest seemed to make observations and use the given mathematical information from the task but were not able to pose a logical question at the end of their posed problem. Additionally, although some students set up a semistructured problem in a real-world context, many were not able to pose a realistic problem. For example, students were allotted $\$ 20$ to be hypothetically spent in Task B, but many students posed problems where the price of the items bought were over $\$ 20$ and yet asked how much money was left at the end of their purchase. Another common occurrence among students $(n=8)$ was the displaying of minor errors. Using our criteria, we classified these problems as non-valid because the setup would not result in obtaining a correct answer if students tried to solve them. However, we believe that these students did improve in their problemposing skills after the intervention because many of them did not possess the knowledge, skills, and confidence necessary to pose a semi-structured problem at the start of the intervention.

Students were encouraged to tell stories during their problem-posing activities. Situating problems in real-world contexts gave students opportunities to get excited about posing (see Figure 5). Because students were excited, they were more motivated during the problem-posing activities. The pre and posttests contained problems where students were encouraged to think about buying food and telling a story about cake being shared. Students posed problems using real-life contexts, and most of the students used their friends' names in their posed problems. Examples of real-life contexts students used include going to a birthday party, their mom baking a cake, sharing a cake between their friends or siblings, or going out for lunch and choosing items from a menu with their friends or family. We believe that the intervention provided students with opportunities to enjoy 
6. You and a friend go to lunch with $\$ 20$. Create a two-step problem using the menu shown. Set up your problem, but do not solve it.

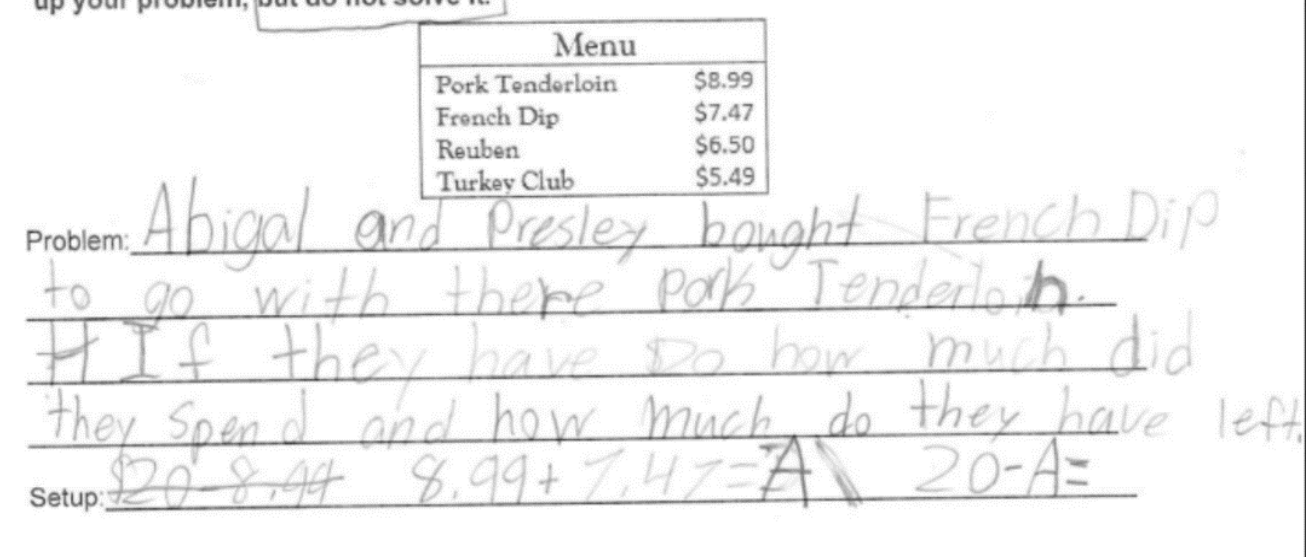

Figure 5. Another student's posed problem for Task B

creating mathematical stories and/or engaging in the learning process, allowing them to pose more sophisticated valid mathematical problems.

\section{LIMITATIONS}

Some of the gains that students made could have been associated with their mathematical understanding at the beginning of the year. Many fourth graders still have a very limited understanding of fractions at the beginning of fourth grade. This limited understanding and lack of prior knowledge of fractions could have possibly had an influence on their lack of ability to pose problems early in the school year on the pretest. Additionally, some students may never have experienced actually going to a restaurant, choosing from a menu, and using paper money to make a payment before. This lack of prior background knowledge could have influenced their scores on the pretest.

\section{DISCUSSION}

Looking at students who improved their problem-posing skills on the posttest specifically allowed researchers to determine that students who were more engaged in hands-on learning with multiple representations in real-world contexts posed more valid problems. This finding is important, as successfully posing problems demonstrates critical higher order thinking skills more so than simply solving problems (Cifarelli \& Sevim, 2015; English, 2020; Van Meter et al., 2020). Higher scores on the posttest also demonstrated improved general mathematical skills. We were able to reliably determine that our intervention made a difference with these 14 struggling students in the current study who had the lowest scores before the intervention and who were able to make substantial improvements, as was shown by their scores, and this was an important finding as well. Thus, building early problem-posing skills at the elementary level may help students build a stronger understanding of mathematical content when they are engaged in authentic learning experiences that are meaningful to their lives (Cai \& Hwang, 2020; Xu et al., 2019).

Therefore, we recommend that teachers employ problem posing as part of their mathematics classroom activities. However, if teachers do not know how to properly implement problem-posing activities and do not employ engaging activities effectively, students' positive progress might not be obtainable. Teacher professional development needs to be provided. Teachers must be reminded to keep in mind that problem posing needs to be centered around students' real-life activities. Additionally, teachers must guide students using hands-on activities with multiple representations in either a whole-class setting or with small groups so students can learn from each other. Using problem-posing activities in mathematics classrooms can allow students opportunities to gain abstract mathematical knowledge and develop their mathematical sophistication while posing valid problems.

Author contributions: All authors have sufficiently contributed to the study, and agreed with the results and conclusions.

Funding: No funding source is reported for this study.

Acknowledgements: Thanks to Drs. Luciana Barroso, Mary Margaret Capraro, Robert M. Capraro, Jamaal Young, and Aggie STEM team for providing the data used for this study.

Declaration of interest: No conflict of interest is declared by authors.

\section{REFERENCES}

Ainsworth, S., Bibby, P., \& Wood, D. (2002). Examining the effects of different multiple representational systems in learning primary mathematics. The Journal of the Learning Sciences, 11(1), 25-61. https://doi.org/10.1207/S15327809JLS1101_2 
Alismail, H. A., \& McGuire, P. (2015). 21st century standards and curriculum: Current research and practice. Journal of Education and Practice, 6(6), 150-154.

Bardini, C., Pierce, R., \& Stacey, K. (2004). Teaching linear functions in context with graphics calculators: Students' responses and the impact of the approach on their use of algebraic symbols. International Journal of Science and Mathematics Education, 2(3), 353-376. https://doi.org/10.1007/s10763-004-8075-3

Bruner, J. S. (1964). The course of cognitive growth. American Psychologist, 19(1), 1-15. https://doi.org/10.1037/h0044160

Cai, J. (2003). Singaporean students' mathematical thinking in problem solving and problem posing: An exploratory study. International Journal of Mathematical Education in Science and Technology, 34(5), $719-737$. https://doi.org/10.1080/00207390310001595401

Cai, J. (2005). U.S. and Chinese teachers' knowing, evaluating, and constructing representations in mathematics instruction. Mathematical Thinking and Learning: An International Journal, 7(2), 135-169. https://doi.org/10.1207/s15327833mtl0702_3

Cai, J., \& Hwang, S. (2020). Learning to teach through mathematical problem posing: Theoretical considerations, methodology, and directions for future research. International Journal of Educational Research, 102. https://doi.org/10.1016/j.ijer.2019.01.001

Cai, J., Moyer, J., Wang, N., Hwang, S., Nie, B., \& Garber, T. (2013). Mathematical problem posing as a measure of curricular effect on students' learning. Educational Studies in Mathematics, 83(1), 57-69. https://doi.org/10.1007/s10649-012-9429-3

Carbonneau, K. K., Marley, S. M., \& Selig, J. P. (2013). A meta-analysis of the efficacy of teaching mathematics with concrete manipulatives. Journal of Educational Psychology, 105(2), 380-400. https://doi.org/10.1037/a0031084

Chapman, O. (2006). Classroom practices for context of mathematics word problems. Educational Studies in Mathematics, 62, 211230. https://doi.org/10.1007/s10649-006-7834-1

Chowrira, S. G., Smith, K. M., Dubois, P. J., \& Roll, I. (2019). DIY productive failure: Boosting performance in a large undergraduate biology course. npj Science of Learning, 4(1). https://doi.org/10.1038/s41539-019-0040-6

Christou, C., Mousoulides, N., Pittalis, M., Pitta-Pantazi, D., \& Sriraman, B. (2005). An empirical taxonomy of problem posing processes. ZDM, 37(3), 149-158. https://doi.org/10.1007/s11858-005-0004-6

Cifarelli, V. V. \& Sevim, V. (2015) Problem posing as reformulation and sense-making within problem solving. In F. H Singer, N. F. Ellerton, \& J. Cai (Eds.), Mathematical problem posing: From research to effective practice (pp. 177-194). Springer. https://doi.org/10.1007/978-1-4614-6258-3_8

Clark, L., \& Clark, J. (2020). Hands-on conics worked for me. The Mathematics Teacher, 113(7), 573-580. https://doi.org/10.5951/mtlt.2019.0010

Cronbach, L. J., \& Shavelson, R. J. (2004). Current thoughts on coefficient alpha and successor procedures. Educational and Psychological Measurement, 64(3), 391-418. https://doi.org/10.1177/0013164404266386

Deliyianni, E., Elia, I., Gagatsis, A., Monoyiou A., \& Panaoura, A. (2009). A theoretical model of students' geometrical figure understanding. In V. Durand-Guerrier, S. Soury-Lavergne, \& F. Arzarello (Eds.), Proceedings of the Sixth Congress of the European Society for Research in Mathematics Education (pp. 366-375). Institut National de Recherche Pédagogique.

English, L. D. (2003). Problem posing in the elementary curriculum. In F. K. Lester, Jr., \& R. I. Charles (Eds.), Teaching mathematics through problem solving: Prekindergarten-Grade 6 (pp. 187-198). National Council of Teachers of Mathematics.

English, L. D. (2020). Teaching and learning through mathematical problem posing: Commentary. International Journal of Educational Research, 102. https://doi.org/10.1016/j.ijer.2019.06.014

Franklin, S., \& Peat, M. (2005). Virtual versus real: An argument for maintaining diversity in the learning environment. International Journal of Continuing Engineering Education and Life Long Learning, 15, 67-78. https://doi.org/10.1504/IJCEELL.2005.006793

Haury, D. L., \& Rillero, P. (1994). Perspectives of hands-on science teaching. The ERIC Clearinghouse for Science, Mathematics, and Environmental Education.

Hidi, S. (1990). Interest and its contribution as a mental resource for learning. Review of Educational Research, 60, $549-572$. https://doi.org/10.3102/00346543060004549

Hoffler, T., \& Leutner, D. (2007). Instructional animation versus static pictures: A meta- analysis. Learning and Instruction, 17(6), 722-738. https://doi.org/10.1016/j.learninstruc.2007.09.013

Holstermann, N., Brube, D., \& Bogeholz, S. (2010). Hands-on activities and their influence on students' interest. Research in Science Education, 40(5), 743-757. https://doi.org/10.1007/s11165-009-9142-0

Holsti, O. (1968). Content analysis. In G. Lindzey \& E. Aronson (Eds.), The handbook of social psychology (2nd ed.). Addison-Wesley.

Huinker, D., \& Bill, V. (2017). Taking action: Implementing effective mathematics teaching practices in K-grade 5. National Council of Teachers of Mathematics.

Kafai, Y. B., Franke, M. L., Ching, C. C., \& Shih, J. C. (1998). Game design as an interactive learning environment for fostering students' and teachers' mathematical inquiry. International Journal of Computers for Mathematical Learning, 3(2), $149-184$.

Kilic, C. (2013). Determining the performances of pre-service primary school teachers in problem posing situations. Educational Sciences: Theory \& Practice, 13(2), 1195-1211.

Kilpatrick, J. (1987). Problem formulating: Where do good problems come from? In A. H. Schoenfeld (Ed.), Cognitive science and mathematics education (pp. 123-147). Erlbaum. 
Krapp, A. (2005). Basic needs and the development of interest and intrinsic motivational orientations. Learning and Instruction, 15(5), 381-395. https://doi.org/10.1016/j.learninstruc.2005.07.007

Kuzle, A., Gebel, I., \& Rott, B. (Eds.). (2018). Proceedings of the 2018 Joint Conference of ProMath and the GDM Working Group on Problem Solving. WTM-Verlag.

Lebuffe, J. R. (1994). Hands-on science in the elementary school. Phi Delta Kappa Educational Foundation. Retrieved from ERIC database. (ED375003)

Lee, J. (2012). Prospective elementary teachers' perceptions of real-life connections reflected in posing and evaluating story problems. Journal of Mathematics Teacher Education, 15(6), 429-452. https://doi.org/10.1007/s10857-012-9220-5

Lesh, R., \& Harel, G. (2003). Problem solving, modeling and local conceptual development. Mathematical Thinking and Learning, 5(2\&3), 157-189. https://doi.org/10.1080/10986065.2003.9679998

Lowrie, T. (2002a). Designing a framework for problem posing: Young children generating open-ended tasks. Contemporary Issues in Early Childhood, 3(3), 354-364. https://doi.org/10.2304/ciec.2002.3.3.4

Lowrie, T. (2002b). Young children posing problems: The influence of teacher intervention on the type of problems children pose. Mathematical Education Research Journal, 14(2), 87-98. https://doi.org/10.1007/BF03217355

Lowrie, T. (2005). Problem solving in technology rich contexts: Mathematics sense making in out-of-school environments. The Journal of Mathematical Behavior, 24(3-4), 275-286. https://doi.org/10.1016/j.jmathb.2005.09.008

Malone, S., Altmeyer, K., Vogel, M., \& Brunken, R. (2020). Homogeneous and heterogeneous multiple representations in equationsolving problems: An eye-tracking study. Journal of Computer Assisted Learning, 36(6), $781-798$. https://doi.org/10.1111/jcal.12426

Mamona-Downs, J., \& Downs, M. (2005). The identity of problem solving. The Journal of Mathematical Behavior, $24,385-401$. https://doi.org/10.1016/j.jmathb.2005.09.011

McHugh, M. L. (2012). Interrater reliability: The kappa statistic. Biochemia Medica, $22(3), \quad 276-282$. https://doi.org/10.11613/BM.2012.031

National Council of Teachers of Mathematics. (2000). Principles and standards for school mathematics.

National Council of Teachers of Mathematics. (2007). Mathematics teaching today: Improving practice, improving student learning! (2nd ed.).

National Council of Teachers of Mathematics. (2020). Catalyzing change in early childhood and elementary mathematics: Initiating critical conversations.

National Research Council. (2001). Adding it up: Helping children learn mathematics. Washington, DC: The National Academies Press. https://doi.org/10.17226/9822

Nott, M., \& Wellington, J. (1996). When the black box springs open: Practical work in schools and the nature of science. International Journal of Science Education, 18, 807-818. https://doi.org/10.1080/0950069960180706

Otten, S., Candela, A. G., de Araujo, Z., Haines, C., \& Munter, C. (Eds.). (2019). Proceedings of the Forty-First Annual Meeting of the North American Chapter of the International Group for the Psychology of Mathematics Education. University of Missouri.

Partnership for 21st Century Learning. (2019). Framework for 21st century learning. http://static.battelleforkids.org/documents/p21/P21_Framework_Brief.pdf

Pedley, T. J. (2005). Applying mathematics. Mathematics Today, 41(3), 79-83.

Porzio, D. T. (1999). Effects of differing emphasis on the use of multiple representations and technology on students' understanding of calculus concepts. Focus on Learning Problems in Mathematics, 21(3), 1-29.

Premadasa, K., \& Bhatia, K. (2013) Real life applications in mathematics: What do students prefer? International Journal for the Scholarship of Teaching and Learning, 7(2). https://doi.org/10.20429/ijsotl.2013.070220

Quintero, E. (2004). Problem posing with multicultural children's literature. Peter Lang.

Silver, E. A. (1994). On mathematical problem posing. For the Learning of Mathematics, 14(1), 19-28.

Silver, E. A., \& Cai, J. (1996). An analysis of arithmetic problem posing by middle school students. Journal for Research in Mathematics Education, 27, 521-539. https://doi.org/10.2307/749846

Silver, E. A., \& Cai, J. (2005). Assessing students' mathematical problem posing. Teaching Children Mathematics, 12(3), 129-135. https://doi.org/10.5951/TCM.12.3.0129

Singer, M. F., Ellerton, N., \& Cai, J. (2013). Problem-posing research in mathematics education: New questions and directions. Educational Studies in Mathematics, 83, 1-7. https://doi.org/10.1007/s10649-013-9478-2

Stillman, G., Brown., J., \& Galbraith, P. (2008). Research into the teaching and learning of applications and modelling in Australasia. In H. Forgasz, A. Barkatsas, A. Bishop, B. Clarke, S. Keast, W. T. Seah, \& P. Sullivan (Eds.), Research in mathematics education in Australasia 2004-2007 (pp. 141-164). Sense Publishers. https://doi.org/10.1163/9789087905019_009

Stoyanova, E., \& Ellerton, N. F. (1996). A framework for research into students' problem posing in school mathematics. In P. C. Clarkson (Ed.), Technology in mathematics education (pp. 518-525). Mathematics Education Research Group of Australasia.

Swafford, J. O., \& Langrall, C. W. (2000). Grade 6 students' preinstructional use of equations to describe and represent problem situations. Journal of Research in Mathematics Education, 11(1), 89-112. https://doi.org/10.2307/749821 
Thorsteinsson, G., \& Page, T. (2018). The standing of hands-on learning in education. Journal on Educational Psychology, 11(3), 111. https://doi.org/10.26634/jpsy.11.3.13873

Ulusoy, F., \& Kepceoğlu, I. (2018). The contextual and cognitive structure of prospective middle school mathematics teachers' problems in semi-structured problem-posing context. Journal of Kirsehir Education Faculty, 19(3), 1937-1963.

Van Meter, P. V., List, A., Lombardi, D., \& Kendeou, P. (Eds.). (2020). Handbook of learning from multiple representations and perspectives. Routledge. https://doi.org/10.4324/9780429443961

Xu, B., Cai, J., Liu, Q., \& Hwang, S. (2019). Teachers' predictions of students' mathematical thinking related to problem posing. International Journal of Educational Research. https://doi.org/10.1016/j.ijer.2019.04.005

Yamamoto, S., Kanbe, T, Yoshida, Y., Maeda, K., \& Hirashima, T. (2012). A case study of learning by problem-posing in introductory phase of arithmetic word problems. Proceedings of the International Conference on Computers in Education, 20, 25-32.

Zbiek, R., \& Connor, A. (2006). Beyond motivation: Exploring mathematical modeling as a context for deepening students' understandings of curricular mathematics. Educational Studies in Mathematics, 63(1), 89-112. https://doi.org/10.1007/s10649005-9002-4 


\section{APPENDIX}

Examples of Lessons

\begin{tabular}{|c|c|c|c|}
\hline Lesson & Representations & Hands-on activity & Real-world topic \\
\hline 1 & Introduction & Candy corn & $\begin{array}{c}\text { Pass out "Writing Good Questions" and candy corn - students pose } \\
\text { questions after placing candy corn in groups }\end{array}$ \\
\hline $3^{\star}$ & Expression cards & Halloween erasers & $\begin{array}{l}\text { Pose problems using expression cards and their Halloween erasers (see } \\
\text { full intervention lesson below) }\end{array}$ \\
\hline 5 & Pictures & $\begin{array}{c}\text { Plastic } \\
\text { farm animals \& dinos }\end{array}$ & $\begin{array}{l}\text { Pose a problem based on one of three pictures: dinos, farm animals, or a } \\
\text { pet shop }\end{array}$ \\
\hline 8 & Pictograph & Coloring graph & Pose a problem based on the pictograph of animals at the zoo \\
\hline 11 & Manipulatives & Easter eggs & $\begin{array}{l}\text { Pick a plastic egg out of the Easter basket and pose a problem based on } \\
\text { the expression inside }\end{array}$ \\
\hline 15 & Manipulatives & Popsicle sticks & $\begin{array}{c}\text { Pick } 6 \text { popsicle sticks: } 3 \text { numbers, } 2 \text { operations (including multiplication or } \\
\text { division), and an equal sign. Pose a 2-step problem after making an } \\
\text { expression with your popsicle sticks. }\end{array}$ \\
\hline 19 & Real-world objects & $\begin{array}{l}\text { Coins, food, and store } \\
\text { ads }\end{array}$ & $\begin{array}{l}\text { Pose a 2-step problem using coins and food store advertisements from the } \\
\text { newspaper }\end{array}$ \\
\hline 20 & Real-world objects & $\$ 10$, menus & $\begin{array}{l}\text { Pose a 2-step problem using } \$ 10 \text { and the menu from various fast food } \\
\text { restaurants }\end{array}$ \\
\hline
\end{tabular}

*Halloween: Adding \& Subtracting Lesson

Review

- Remind students to focus on thinking through a plan before starting to solve a problem.

Model

- Use the example and the erasers to model the problem-solving procedure for the students.

Introduce adding and subtracting using concrete models

- Students will each have a part-part-whole board.

- They will pick an expression card and use the erasers to model that expression on the board and solve.

Posing

- Using the erasers, have students pose their own problems.

- Once the word problem is written, students should set up how to solve the problem. They do not have to find the answer.

- If students are struggling, encourage them to use the question stems.

Share

- Can we solve this problem? Why or why not? What is missing? Etc.

Close

- Summarize and review what you worked on today and discuss how you they can use concrete objects to help them solve problems. 